\title{
Increased DNA Fragmentation in Patients with Infertility in Dakar (Senegal)
}

\author{
Mama Sy Diallo1*, Oumar Faye1, Abdoulaye Séga Diallo1, Yoro Diallo², Babacar Diao³ \\ ${ }^{1}$ Cytogenetic and Reproductive Biology Laboratory, University Teaching Hospital Aristide Le Dantec, Dakar, \\ Senegal \\ ${ }^{2}$ Department of Urology, Faculty of Health Sciences, University of Thies, Thies, Senegal \\ ${ }^{3}$ Urology and Andrology Unit, University Teaching Hospital Aristide Le Dantec, Dakar, Senegal \\ Email: *mamatasy@yahoo.fr
}

Received 12 October 2015; accepted 21 November 2015; published 24 November 2015

Copyright (C) 2015 by authors and Scientific Research Publishing Inc.

This work is licensed under the Creative Commons Attribution International License (CC BY).

http://creativecommons.org/licenses/by/4.0/

(c) (i) Open Access

\section{Abstract}

The presence of DNA fragmentation in semen is associated with poor results in ART (Assisted Reproductive Technology). This has led to the introduction of sperm DNA integrity testing in the clinical assessment of male infertility. The TUNEL assay is one of the most commonly used tests to measure DNA fragmentation in research studies, but it is now being optimized for routine clinical use. So, the objectives of our study were to install the TUNEL assay in our laboratory and to use it to assess the degree of DNA fragmentation in our patients dealing with couple infertility. Forty seven (47) and 25 samples from patients followed up for infertility and known fertile men were analyzed between August 2013 and July 2015 respectively. The sperm samples were evaluated according to the World Health Organization Guidelines. Sperm DNA damage was assessed by the TUNEL assay, with a standardized protocol that we adapted for reading using fluorescence microscopy instead of flow cytometry. The Sperm DNA Fragmentation Index was significantly higher in patients with infertility compared to the controls $(22.2 \% \pm 5.6 \%$ vs. $16.7 \% \pm 0.7 \%)$ with a $p<0.05$. This Index was also high in patients with varicocele compared to the control group $(22.8 \% \pm 9.2 \mathrm{vs}$. $16.7 \% \pm 0.7 \%)(p<0.01)$. After establishing the ROC curve (Receiver Operating Characteristics curve), we found a 15\% threshold of DNA fragmentation, separating the patients with infertility from the control group. In our study, a 15\% threshold positivity of DNA fragmentation using the TUNEL assay was highly associated with infertility. The results indicate that high level DNA fragmentation is associated with infertility.

\section{Keywords}

DNA Fragmentation, TUNEL Assay, Fluorescence Microscopy

\footnotetext{
"Corresponding author.
} 


\section{Introduction}

DNA damage in spermatozoa is considered as an important cause of male infertility [1]. The presence of DNA fragmentation in semen is associated with poor results in the ART (Assisted Reproductive Technology) ([2]-[4]). High DNA fragmentation levels have a negative influence on cleavage rates, embryo quality and pregnancy outcomes in IVF (In Vitro Fertilization) as well as in ICSI (Intracytoplasmic Sperm Injection) [5]. To overcome this abnormality, the oocyte is well known for its capacity to repair DNA damage in the spermatozoa [6]. However, it seems that this capacity is limited, especially when the level of DNA damaged is too high [7].

Standard semen analysis does not give information on DNA integrity and during the ICSI procedure, only one spermatozoon is chosen for injection, depending on its morphology. Whereas a spermatozoon is considered to be normal morphologically, it can possess considerable DNA damage, which can result in genetically transmitted abnormality. Lots of lab tests have been used to evaluate DNA fragmentation in the spermatozoa. Some of them give quantitative results, while others give more qualitative results [7]. The two most commonly used are SCSA (Sperm Chromatin Structure Assay) and the TUNEL test (terminal deoxynucleotidyl transferase mediated dUTP nick end labeling assay). The TUNEL assay measures both single and double strand DNA fragmentation, at specific points (the free 3'hydroxyl groups). It is a direct quantification of sperm DNA breaks and the results can be compared with other studies using the same assay. However, proposed thresholds differ in literature and at the moment; there are no clear consensus on threshold values [8]. The TUNEL assay is still being optimized, for example, Sharma et al. [8] and Sergerie et al. [9] have proposed a methodology to standardize TUNEL test for routine clinical use. They have established their threshold values at $19.25 \%$ and $20 \%$ respectively and these can be used to install the TUNEL assay. They both used flow cytometry to read the results. With the TUNEL assay, the reading of the results can also be performed with a fluorescence microscope [10] [11], but the reported thresholds are lower [11] [12].

In this preliminary study, we are optimizing the TUNEL assay. One of our goals was to propose a threshold specific to our laboratory, for future routine clinical use. We also wanted to assess the degree of DNA fragmentation found in our patients dealing with couple infertility.

\section{Material and Methods}

\subsection{Patients}

This is a prospective study. Semen samples from 72 patients attending the Reproductive Biology and Genetics laboratory in Dakar at the University teaching hospital, Aristide Le Dantec in Dakar between August 2013 and July 2015. The control samples $(n=25)$ were collected from men who fathered within less than two years with normozoospermia values after semen analysis. The other patients consisted of those being followed up for infertility $(n=47)$ and among them 23 were treated for varicocele. Consent was obtained from all of them and the study was approved by the ethical committee.

\subsection{Semen Analysis}

We collected semen samples after $72 \mathrm{~h}$ of sexual abstinence . The analysis was performed 30 min after collection, according to the WHO latest guideline (2010). So the analysis included sperm concentration, motility, vitality and leukocyte concentration. Sperm morphology was assessed using David's Criteria .We classified semen samples into normal or abnormal on the basis of the analysis, using the reference values from the WHO guidelines for semen analysis (2010) [13].

\subsection{Sample Collection and Storage}

Fresh samples with 5 million spermatozoa were collected. When the total sperm count was less than 5 million, the whole sample was used without dilution. The samples were then centrifuged (at $600 \mathrm{~g}$ for 10 minutes) and the supernatant (the seminal plasma) was discarded.

The pellet was suspended in $1 \mathrm{ml}$ of PBS (Phosphate Buffered Saline, pH 7.4) and fixed with a with a 4\% solution of paraformaldehyde (30 minutes at room temperature).Then, the spermatozoa were again washed to remove the paraformaldehyde and suspended in a (Methanol/acid acetic) mixture ( 3 volumes to 1 ) and stored at $-20^{\circ} \mathrm{C}$ until the run time. 


\subsection{TUNEL Assay for DNA Fragmentation}

Sperm DNA fragmentation was quantified by using the terminal deoxynucleotidyl transferase-mediated fluorescein-dUTP nick end labeling assay kit "In-situ Cell Death Detection Kit" (Roche Diagnostics, GmbH, Mannheim, Germany).

After a wash in PBS to remove the (Methanol/acid acetic) mixture, the sperm pellet was suspended in $1 \mathrm{ml}$ of distilled water with $0.1 \%$ Triton X-100 in $0.1 \%$ sodium citrate for permeabilization (10 minutes at room temperature).

After another wash with PBS (at $300 \mathrm{~g}$ for $5 \mathrm{~min}$ ), we obtained a pellet that was suspended in the staining solution containing labeled nucleotides and enzyme terminal transferase. This mixture was kept in a dark room at 37 degrees for 1 hour. Negative and positive controls were included for each run. They were performed, omitting the enzyme terminal transferase and pre-incubating fixed permeabilized sperm samples with DNase I (1 $\mathrm{mg} / \mathrm{ml}$ ) for $20 \mathrm{~min}$ at room temperature, respectively. After the reaction (Hybridization), the cells were washed twice in PBS (at $300 \mathrm{~g}$ for $5 \mathrm{~min}$ ) and suspended in $0.5 \mathrm{ml}$ of DAPI solution (4', 6'-diamidino-2-phenylindole) for counterstaining ( 30 minutes in the dark, at room temperature). The suspension was centrifuged (at $300 \mathrm{~g}$ for 5 $\min$ ), and the pellet resuspended in $100 \mu$ of PBS. The samples were smeared on super frost slides and mounted with Vectashield ${ }^{\circledR}$ (Vector laboratories, Inc.).

\subsection{Fluorescence Microscopy}

The slides were examined by fluorescence microscopy with a DAPI filter and a Fluoroscein Isothiocyanate (FITC) filter. Five hundred (500) spermatozoa were examined. DNA fragmented spermatozoa appeared green while normal DNA was blue due to DAPI staining. The fragmentation percentage was the total number of cells with green fluorescence over the total of counted cells (blue fluorescence).

\subsection{Statistical Analysis}

Two Groups were compared (the control group of men with proven fertility and the group with infertility). The results are expressed as mean \pm SD. The data was analyzed by Student's test, when the studied variable had a normal distribution. To compare means of DNA fragmentation we used the test of Wilcoxon Mann-Whitney. To establish a threshold of positivity, we drew a ROC curve with the weight of specificity and sensibility values. The analyses were performed using the software $\mathrm{R}$ version 3.2.2 for windows.

\section{Results}

\subsection{Clinical Characteristics of Our Patients}

The mean age of our patients was 33. $2 \pm 5.7$ years (range 20 - 46) in the control group and $35.7 \pm 5.2$ (range 23 63 ) in the group of infertile patients. There was no statistical difference between the two groups with age as a consideration $(\mathrm{p}>0.05)$. The mean infertility period was 27 months \pm 9 months. The majority of these patients were affected by primary infertility ( $62.2 \%$ of cases). The main factor of infertility in our series was varicocele with $(48.9 \%)$ of cases, followed by urogenital tract infection $(n=12)$ and exposure to toxics $(n=4)$. The patients considered as exposed to toxics were, user of pesticide, 2 patients receiving treatment for pulmonary tuberculosis and one smoker (Figure 1).

\subsection{Results of Semen Analysis}

The sperm parameters are presented in Table 1 . In the group of patients with infertility we found no correlation between semen parameters and DNA fragmentation index (Table 2). In 5 cases, we found a high level of DNA fragmentation (over 15\%) with normal semen parameters. It involved patients being followed up for infertility ( 3 cases of varicocele who underwent a surgical intervention and 2 cases of infertility of undetermined etiology).

\subsection{Measurement of DNA Damage}

The level of Sperm DNA fragmentation was significantly higher in infertile patients compared to the control group $(22.2 \% \pm 5.6 \%$ vs. $16.7 \% \pm 0.7 \%)$ with $\mathrm{p}<0.05$ (Table 3 ). The level of Sperm fragmentation was higher 

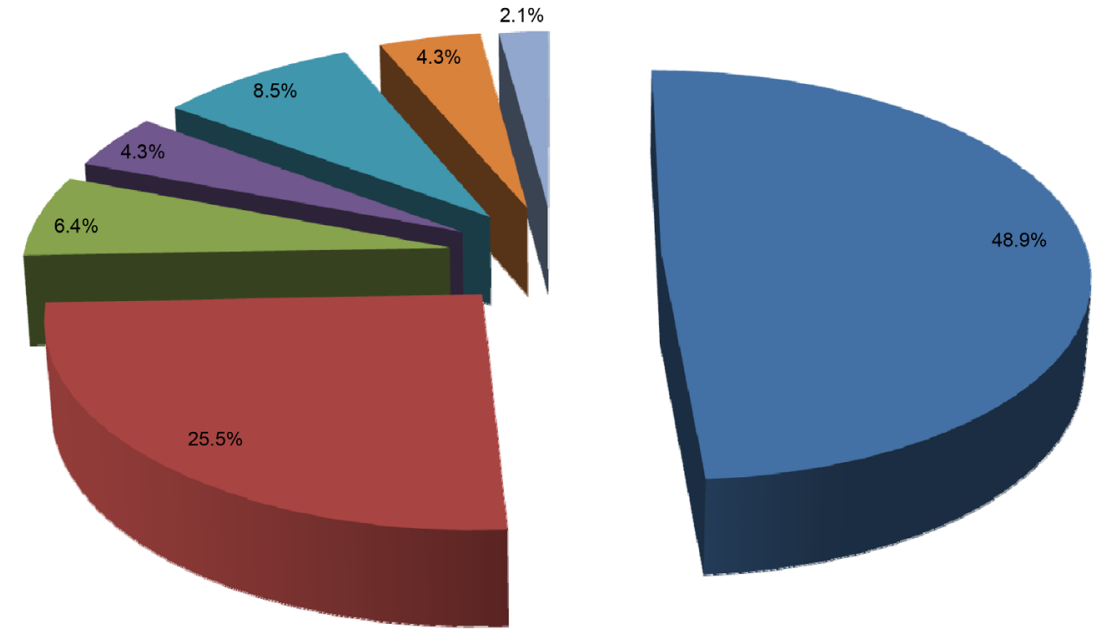

- Varicocele $(n=23)$

- Infection ( $\mathrm{n}=12$ )

- Inguinal Hernia $(n=3)$

cryptorchidia $(\mathrm{n}=2)$

toxic exposition $(n=4)$

- Unknown etiology $(n=2)$

testicular traumatism $(n=1)$

Figure 1. Repartition of the different etiologies of infertility in our sample.

Table 1. Semen characteristics in control subjects and patients with infertility.

\begin{tabular}{cccc}
\hline & & Infertile patients (n= 47) & \\
\cline { 3 - 3 } Semen parameters & Controls $(\mathbf{n}=\mathbf{2 6})$ & $\begin{array}{c}\text { Normal semen parameters (SP) } \\
(\mathbf{n}=\mathbf{1 4})\end{array}$ & $\begin{array}{c}\text { Abnormal semen } \\
\text { parameters (SP) }(\mathbf{n}=\mathbf{3 3})\end{array}$ \\
\hline Volume (ml) & $2.6 \pm 1.8$ & $2.8 \pm 1.6$ & $2.1 \pm 1.9$ \\
Concentration (millions/ml) & $150.3 \pm 28.4$ & $85 \pm 45.2$ & $32.2 \pm 29.1$ \\
Progressive motility (\%) (a + b) & $65 \pm 5.5$ & $55 \pm 10.5$ & $40 \pm 15.2$ \\
Vitality (\%) & $68.3 \pm 5.6$ & $58.1 \pm 7.8$ & $45.2 \pm 18.4$ \\
$\begin{array}{c}\text { Typical forms (\%) morphology } \\
\text { with David's criteria }\end{array}$ & $34.2 \pm 7.6$ & $32.7 \pm 5.1$ & $20.8 \pm 5.4$ \\
\hline
\end{tabular}

Table 2. DNA fragmentation according to the semen parameters.

\begin{tabular}{ccc}
\hline Infertile patients $(\mathbf{n}=\mathbf{4 7})$ & $\begin{array}{c}\text { Normal semen parameters } \\
(\mathbf{n}=\mathbf{1 4})\end{array}$ & $\begin{array}{c}\text { Abnormal semen parameters } \\
(\mathbf{n}=\mathbf{3 3})\end{array}$ \\
\hline DNA fragmentation $(\%)$ & $37.5 \pm 6.1$ & $42.9 \pm 6.8$ \\
\hline
\end{tabular}

Table 3. Comparison of DNA fragmentation between controls and patients with infertility.

\begin{tabular}{cccc}
\hline & Control $(\mathbf{n}=\mathbf{2 6})$ & Patients with infertility $(\mathbf{n}=\mathbf{4 7})$ & p value \\
\hline DNA fragmentation $(\%)$ & $16.7 \pm 0.7$ & $22.2 \pm 5.6$ & $<0.01$ \\
\hline
\end{tabular}

in the group of patients with varicocele compared to the control group $(22.8 \% \pm 9.2 \%$ vs. $16.7 \% \pm 0.7 \%)(p<$ 0.01) (Table 4).

We compared the level of DNA fragmentation in varicocele with the mean average DNA fragmentation in the group with other etiologies of infertility $(19.9 \% \pm 5.6 \%)$. There was no difference from a statistical point of view ( $p>0.05$ ) (Table 5). The highest level of DNA fragmentation was found in the case of testicular traumatism $(28 \% \pm 0 \%)$, followed by the group with repaired inguinal hernia $(25 \% \pm 5.6 \%)$ and then by the group with varicocele $(22.8 \% \pm 9.2 \%)$. The variation of the level of DNA fragmentation according to the etiology of the infertility is represented by the graph in Figure 2. We found a 15\% threshold of DNA fragmentation with an accuracy of $72.1 \%$, after establishing the ROC curve. The sensitivity was $87.2 \%$ with a CI (Confidence Interval) of 95\% at that point (Figure 3). We found a PPV (Positive Predictive Value) of 73.2\% and a NPV (Negative Predictive Value) of $68.4 \%$. 
Table 4. Comparison of DNA fragmentation between controls and patients with varicocele.

\begin{tabular}{cccc}
\hline & Controls $(\mathbf{n}=\mathbf{2 6})$ & Varicocele & p value \\
\hline DNA fragmentation (\%) & $16.7 \pm 0.7$ & $22.8 \pm 9.2$ & $<0.01$ \\
\hline
\end{tabular}

Table 5. Comparison of DNA fragmentation between patients with varicocele and patients with another etiology for infertility.

\begin{tabular}{cccc} 
& Varicocele $(\mathbf{n}=\mathbf{2 3})$ & Other etiologies of infertility $(\mathbf{n}=\mathbf{2 4})$ & $\mathbf{p}$ value \\
\hline DNA fragmentation $(\%)$ & $22.8 \pm 9.2$ & $19.9 \pm 5.6$ \\
\hline
\end{tabular}

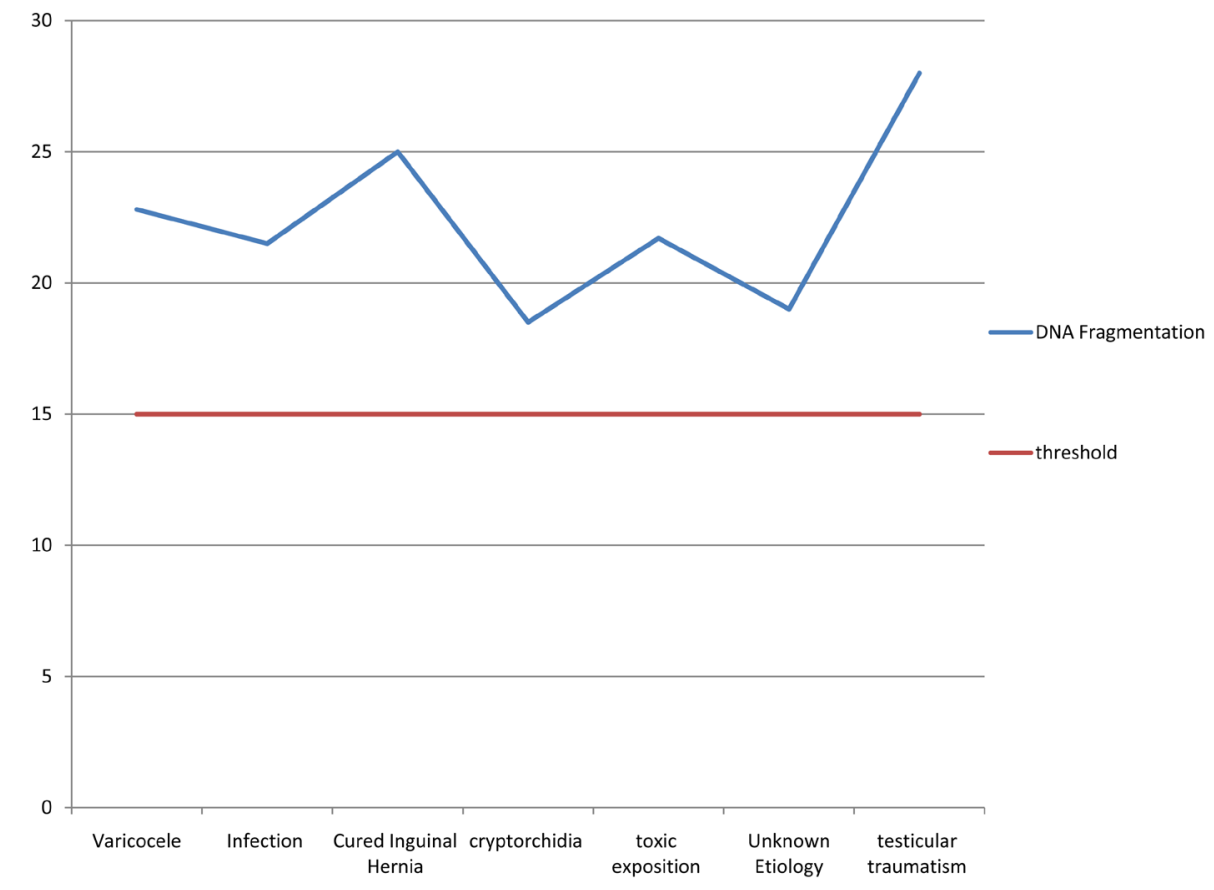

Figure 2. Variations of DNA fragmentation percentage among infertile patients.

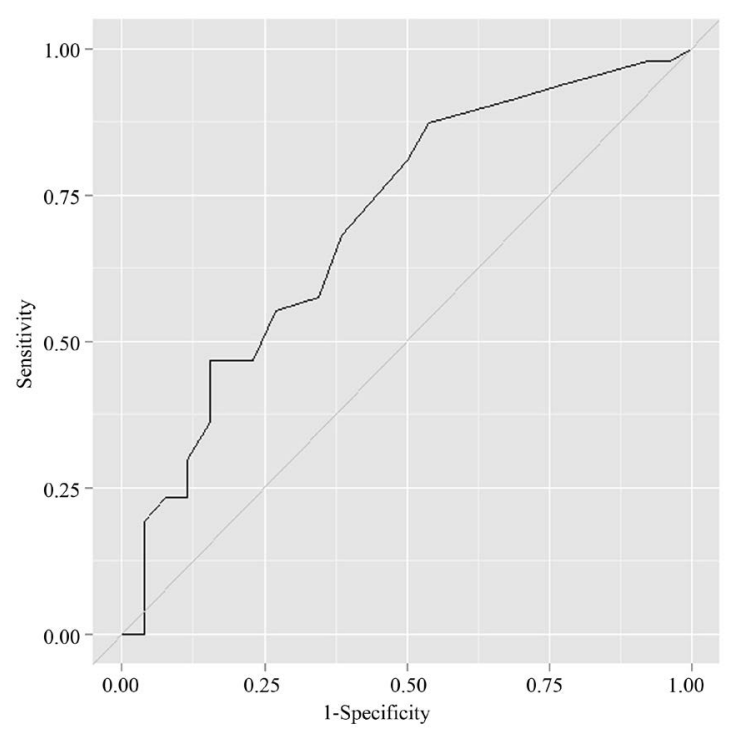

Figure 3. Receiver operating characteristics curve at $15 \%$ sperm DNA fragmentation. 


\section{Discussion}

The described mechanisms responsible for DNA fragmentation in the human sperm are multiple. The following processes are implicated: apoptosis in the seminiferous tubule epithelium, defects in chromatin remodeling during the process of spermatogenesis, accumulation of oxygen radicals, induced DNA damage during sperm migration from the seminiferous tubules to the epididymis, the activation of sperm caspases and endonucleases, damage induced by chemotherapy and radiotherapy, and the effect of environmental toxicants [7]. DNA damage seems to have a bad impact on the outcome of ART (Assisted Reproductive Technology) [1]. This state is associated with poor fertilization rates and bad embryo development [11] [14]. Sperm DNA fragmentation is increasingly being recognized as an important factor of infertility [15] and is widely investigated [15]. This fact has led to the introduction of sperm DNA integrity testing to the clinical assessment of male infertility (The practice committee, 2013) [16].

In our study, varicocele represented nearly half of the cases of infertility (48.9\%). The level of DNA fragmentation was high compared to the control group. Varicocele is implicated in $30 \%$ to $35 \%$ of men with primary infertility [17] and several studies have reported that varicocele is associated with increased sperm DNA damage [18]-[21]. It is proven that fragmentation is also reversible, and some authors noticed decreased levels after a surgical intervention [22]-[25]. The pathogenetic mechanisms by which varicocele induces testicular dysfunction and infertility are not completely understood but at the biological level, varicocele was found to be associated with high levels of seminal oxidative stress, as evidenced by increased levels of ROS (Reactive Oxygen Species) and reduced total antioxidant capacity (TAC) [26]-[28]. In addition, oxidative stress has been shown to affect the integrity of the sperm genome by causing high frequencies of single and double strand DNA breaks which are often detected in the ejaculates of infertile men [20] [29]. Oxidative stress has also been correlated with apoptosis [30] [31]. Oxidative Stress and Apoptosis are both two mechanisms implicated in DNA fragmentation [7] so their presence could explain high levels of DNA damage in varicocele.

We did not find any statistical difference in levels of DNA fragmentation in the group with good semen parameters and the group with poor semen parameters. Some authors found a positive correlation between as thenozoospermia and DNA fragmentation [7] [32] [33]. This correlation is still a subject of controversy because there are studies that have reported that there is none [34] [35].

The infertile patients in our results had a high mean level of DNA fragmentation $(p<0.05)$. We obtained a ROC curve at $15 \%$ DNA fragmentation separating the control group from the group of patients with infertility but this his data was obtained with an area under the curve at 0.71 . We found a threshold which is lower than that given in Sharma's study [8] (19.25\%) and in Sergerie's (20\%) [9]. This can be due to the fact that our cohort was smaller $(n=47)$. Even if, we used the test of Wilcoxon-Mann-Whitney to correct that bias, this must be taken into account while interpreting our first results. A study with a lager cohort, following the same methodology, would give more accuracy to our threshold.

Another reason could be the fact that we used fluorescence microscopy to measure the level of fragmentation instead of cytometry.

Even, if Values of sensitivity and specificity are due to the intrinsic performance of the TUNEL test [9], the different thresholds reported in literature could be the results of interpreting the TUNEL assay by either fluorescence microscopy or cytometry (14\% to $25 \%$ [11] [12]) and (20\% to $40 \%)$ respectively [35] [36].

That is the reason why, some authors like Dominguez et al. [37] performed double reading of slides by cytometer for the same samples $(n=66)$ after TUNEL assay. He found a good correlation between the two results but the results after reading by cytometer were 2.6 higher than the one obtained on the slides by Murotari et al. [38] who found the same results with a ratio of 1.6 in a previous study with fewer numbers of subjects [35].

Cytometry is said to be better, for standardization, because it can analyze a larger amount of cells and it minimizes the intra and interobserver's variations, but the calibration is very important and some authors like Murotari et al. [38] found some bias in cytometry. According to her, the biases are due to the inability of Flow Cytometer to recognize analyzed cells morphologically. They consist in the presence of non-sperm elements (such as M540 bodies that are round semen structures exhibiting with forward-scattered light (FSC) and side-scattered light (SSC) properties similar to spermatozoa. False negative sperm (such as the fraction of brighter sperm masked by the autofluorescence of the dimmer ones, in certain subjects), and possibly, false TUNEL-positive sperm.

The advantage of the reading on slides is that the cells are clearly identified. This visualization of the cells can allow other labeling with specific probes to perform another diagnosis during the same procedure. For example 
Kalyuzhny et al. [39] employed a parallel assay that would confirm whether cells experiencing oxidative damage undergo apoptosis and detected oxidative damage and apoptosis at a single-cell level.

According to Mitchell et al. [40] T.U.N.E.L assay underestimates DNA damage in human spermatozoa. He proposed a modified protocol with the use of dithiothreitol to increase the accessibility of terminal deoxynucleotidyl transferase (Tdt) to the sites of DNA cleavage. However, as, explained by Sharma in his study [8], this assay, unfortunately, doesn't give any information regarding the particular genes that may be affected by DNA fragmentation, and cannot differentiate normal breaks from pathologic ones.

To compare the results of the studies on DNA fragmentation, or to establish good meta-analyses, a great number of factors must be taken into consideration such as the technic used and the method of reading the results. For example, in the same assay, as in TUNEL, there will be threshold variations depending on the use of fluorescence microscopy or cytometry for interpreting the results even if there is o good concordance between the two. Inter individual variations should also be considered. Sergerie et al. reported a variation of the mean level of DNA fragmentation in the same healthy patients during 10 years. This variation was between $1.4 \%$ and $18.6 \%$ but always under the $19 \%$ threshold [41].

For the moment we found a $15 \%$ threshold and this value is in concordance with the ones found in literature using the same assay. More studies, including a larger cohort and specially taking into account the positive and the negative predictive value of DNA fragmentation in the outcome of pregnancy in the patients with infertility have to be performed. Varicocele seems to be a good model of study to better understand the biological mechanisms of DNA fragmentation and its influence on the outcome of a pregnancy.

\section{Conclusion}

We found an increased level of DNA fragmentation in our patients dealing with couple infertility. We used TUNEL assay and fluorescence microscopy to measure DNA fragmentation. We followed a standardized method and found a $15 \%$ threshold with an accuracy of $72.1 \%$. We plan to have a larger cohort to assess this finding and to establish a threshold adapted to our laboratory and to the profile of our patients.

\section{Conflict of Interest}

There is no conflict of interest.

\section{References}

[1] Aitken, R.J., Irvine, D.S. and Wu, F.C. (1991) Prospective Analysis of Sperm-Oocyte Fusion and Reactive Oxygen Species Generation as Criteria for the Diagnosis of Infertility. American Journal of Obstetrics and Gynecoly, 164, 542551. http://dx.doi.org/10.1016/S0002-9378(11)80017-7

[2] Benchaib, M., Braun, V., Lornage, J., Hadj, S., Salle, B., Lejeune, H. and Guérin, J.F. (2003) Sperm DNA Fragmentation Decreases the Pregnancy Rate in an Assisted Reproductive Technique. Human Reproduction, 18, 1023-1028. http://dx.doi.org/10.1093/humrep/deg228

[3] Bungum, M., Humaidan, P., Spano, M., Jepson, K., Bungum, L. and Giwercman, A. (2004) The Predictive Value of Sperm Chromatin Structure Assay (SCSA) Parameters for the Outcome of Intrauterine Insemination, IVF and ICSI. Human Reproduction, 19, 1401-1408. http://dx.doi.org/10.1093/humrep/deh280

[4] Carrell, D.T., Liu, L., Peterson, C.M., Jones, K.P., Hatasaka, H.H., Erickson, L. and Campbell, B. (2003) Sperm DNA Fragmentation Is Increased in Couples with Unexplained Recurrent Pregnancy Loss. Archives of Andrology, 49, 49-55. http://dx.doi.org/10.1080/01485010290099390

[5] Zini, A., Blumenfeld, A., Libman, J. and Willis, J. (2005) Beneficial Effect of Microsurgical Varicocelectomy on Human Sperm DNA Integrity. Human Reproduction, 20, 1018-1015.

[6] Ahmadi, A. and Ng, S.C. (1999) Fertilizing Ability of DNA-Damaged Spermatozoa. Journal of Experimental Zoology, 284, 696-704. http://dx.doi.org/10.1002/(sici)1097-010x(19991101)284:6<696::aid-jez11>3.0.co;2-e

[7] Sakkas, D. and Alvarez, J.G. (2010) Sperm DNA Fragmentation: Mechanisms of Origin, Impact on Reproductive Outcome, and Analysis. Fertility and Sterility, 93, 1027-1036. http://dx.doi.org/10.1016/j.fertnstert.2009.10.046

[8] Sharma, R.K., Sabanegh, E., Mahfouz, R., Gupta, S., Thiyagarajan, A. and Agarwal, A. (2010) TUNEL as a Test for Sperm DNA Damage in the Evaluation of Male Infertility. Journal of Urology, 76, 1380-1386. http://dx.doi.org/10.1016/j.urology.2010.04.036

[9] Sergerie, M; Laforest, G., Bujan, L., Bissonnette, F. and Bleau, G. (2005) Sperm DNA Fragmentation: Threshold 
Value in Male Fertility. Human Reproduction, 20, 3446-3451. http://dx.doi.org/10.1093/humrep/dei231

[10] Henkel, R., Kierspel, E., Hajimohammad, M., Stalf, T., Hoogendijk, C., Mehnert, C., Menkveld, R, Schill, W.B. and Kruger, T.F. (2004) DNA Fragmentation of Spermatozoa and Assisted Reproduction Technology. Reproductive Biomedicine Online, 7, 477-484. http://dx.doi.org/10.1016/S1472-6483(10)61893-7

[11] Benchaib, M., Lornage, J., Mazoyer, C., Lejeune, H., Salle, B. and Guerin, J.F. (2007) Sperm Deoxyribonucleic Acid Fragmentation as a Prognostic Indicator of Assisted Reproductive Technology Outcome. Fertility and Sterility, 87, 93100.

[12] Gandini, L., Lombardo, F., Paoli, D., Caponecchia, L., Familiari, G., Verlengia, C., Dondero, F. and Lenzi, A. (2000) Study of Apoptotic DNA Fragmentation in Human Spermatozoa. Human Reproduction, 15, 830-839.

[13] WHO (2010) Laboratory Manual for the Examination and Processing of Human Semen. WHO Press, 5, 113.

[14] Avendaño, C. and Oehninger, S. (2011) DNA Fragmentation in Morphologically Normal Spermatozoa: How Much Should We Be Concerned in the ICSI Era? Journal of Andrology, 32, 356-363. http://dx.doi.org/10.2164/jandrol.110.012005

[15] Komiya, A., Kato, T., Kawauchi, Y., Watanabe, A. and Fuse, H. (2014) Clinical Factors Associated with Sperm DNA Fragmentation in Male Patients with Infertility. Scientific World Journal, 2014.

[16] Practice Committee of the American Society for Reproductive Medicine (2013) The Clinical Utility of Sperm DNA Integrity Testing: A Guideline. Fertility and Sterility, 99, 673-677.

[17] Choi, W.S. and Kim, S.W. (2013) Current Issues in Varicocele Management: A Review. The World Journal of Men's Health, 31, 12-20. http://dx.doi.org/10.5534/wjmh.2013.31.1.12

[18] Saleh, R.A., Agarwal, A., Nada, E.A., El-Tonsy, M.H., Sharma, R.K., Meyer, A., Nelson, D.R. and Thomas, A.J. (2003) Negative Effects of Increased Sperm DNA Damage in Relation to Seminal Oxidative Stress in Men with Idiopathic and Male Factor Infertility. Fertility and Sterility, 79, 1597-1605.

[19] Blumer, C.G., Fariello, RM., Restelli, A.E., Spaine, D.M., Bertolla, R.P. and Cedenho, A.P. (2008) Sperm Nuclear DNA Fragmentation and Mitochondrial Activity in Men with Varicocele. Fertility and Sterility, 90, 1716-1722.

[20] Wang, X., Sharma, R.K., Sikka, S.C., Thomas Jr., A.J., Falcone, T. and Agarwal, A. (2003) Oxidative Stress Is Associated with Increased Apoptosis Leading to Spermatozoa DNA Damage in Patients with Male Factor Infertility. Fertility and Sterility, 80, 531-535. http://dx.doi.org/10.1016/S0015-0282(03)00756-8

[21] Smith, R., Kaune, H., Parodi, D., Madariaga, M., Rios, R., Morales, I. and Castro, A. (2006) Increased Sperm DNA Damage in Patients with Varicocele: Relationship with Seminal Oxidative Stress. Human Reproduction, 21, 986-993. http://dx.doi.org/10.1093/humrep/dei429

[22] Smit, M., Romijn, J.C., Wildhagen, M.F., Veldhoven, J.L., Weber, R.F. and Dohle, G.R. (2010) Decreased Sperm DNA Fragmentation after Surgical Varicocelectomy Is Associated With Increased Pregnancy Rate. Journal of Urology, 183, 270-274.

[23] Li, F., Yamaguchi, K., Okada, K., Matsushita, K., Ando, M., Chiba, K., Yue, H. and Fujisawa, M. (2012) Significant Improvement of Sperm DNA Quality after Microsurgical Repair of Varicocele. Systems Biology in Reproductive Medecine, 58, 274-277. http://dx.doi.org/10.3109/19396368.2012.692431

[24] Kadioglu, T.C., Aliyev, E. and Celtik, M. (2014) Microscopic Varicocelectomy Significantly Decreases the Sperm DNA Fragmentation Index in Patients with Infertility. BioMed Research International, 2014. http://dx.doi.org/10.1155/2014/695713

[25] Werthman, P., Wixon, R., Kasperson, K.B.S. and Evenson, D.P. (2008) Significant Decrease in Sperm Deoxyribonucleic Acid Fragmentation after Varicocelectomy. Fertility and Sterility, 90, 1800-1804. http://dx.doi.org/10.1016/i.fertnstert.2006.09.019

[26] Pasqualotto, F.F., Sharma, R.K., Nelson, D.R., Thomas, A.J. and Agarwal, A. (2000) A Relationship between Oxidative Stress, Semen Characteristics, and Clinical Diagnosis in Men Undergoing Infertility Investigation. Fertility and Sterility, 73, 459-464. http://dx.doi.org/10.1016/S0015-0282(99)00567-1

[27] Zini, A., Finelli, A., Phang, D. and Jarvi, K. (2000) Influence of Semen Processing Technique on Human Sperm DNA Integrity. Urology, 56, 1081-1084.

[28] Agarwal, A., Saleh, R.A. and Bedaiwy, M.A. (2003) Role of Reactive Oxygen Species in the Pathophysiology of Human Reproduction. Fertility and Sterility, 79, 829-843. http://dx.doi.org/10.1016/S0015-0282(02)04948-8

[29] Moustafa, M.H., Sharma, R.K., Thornton, J., Mascha, E., Abdel-Hafez, M.A., Thomas Jr., A.J. and Agarwal, A. (2004) A Relationship between ROS Production, Apoptosis and DNA Denaturation in Spermatozoa from Patients Examined for Infertility. Human Reproduction, 19, 129-138.

[30] Higuchi, Y. (2003) Chromosomal DNA Fragmentation in Apoptosis and Necrosis Induced by Oxidative Stress. Biochemical Pharmacology, 66, 1527-1535. http://dx.doi.org/10.1016/S0006-2952(03)00508-2 
[31] Kwon, Y.W., Masutani, H., Nakamura, H., Ishii, Y. and Yodoi, J. (2003) Redox Regulation of Cell Growth and Cell Death. Biological Chemistry, 384, 991-996. http://dx.doi.org/10.1515/bc.2003.111

[32] Sills, E.S., Fryman, J.T., Perloe, M., Michels, K.B. and Tucker, M.J. (2004) Chromatin Fluorescence Characteristics and Standard Semen Analysis Parameters: Correlations Observed in Andrology Testing among 136 Males Referred for Infertility Evaluation. Journal of Obstetrics and Gynaecoly, 24, 74-77.

[33] Cohen-Bacrie, P., Belloc, S., Ménézo, Y.J., Clement, P., Hamidi, J. and Benkhalifa, M. (2009) Correlation between DNA Damage and Sperm Parameters: A Prospective Study of 1633 Patients. Fertility and Sterility, 91, 1801-1805. http://dx.doi.org/10.1016/j.fertnstert.2008.01.086

[34] Saleh, R.A., Agarwal, A., Nelson, D.R., Nada, E.A., El-Tonsy, M.H., Alvarez, J.G., Thomas Jr., A.J. and Sharma, R.K. (2002) Increased Sperm Nuclear DNA Damage in Normozoospermic Infertile Men: A Prospective Study. Fertility and Sterility, 78, 313-318. http://dx.doi.org/10.1016/S0015-0282(02)03219-3

[35] Muratori, M., Piomboni, P., Baldi, E., Filimberti, E., Pecchioli, P., Moretti, E., Gambera, L., Baccetti, B., Biagiotti, R., Forti, G. and Maggi, M. ( 2000) Functional and Ultrastructural Features of DNA-Fragmented Human Sperm. Journal of Andrology, 21, 903-912.

[36] Erenpreiss, J., Jepson, K., Giwercman, A., Tsarev, I., Erenpreisa, J. and Spano, M. (2004) Toluidine Blue Cytometry Test for Sperm DNA Conformation: Comparison with the Flow Cytometric Sperm Chromatin Structure and TUNEL Assays. Human Reproduction, 19, 2277-2282.

[37] Domínguez-Fandos, D., Camejo, M.I., Ballescà, J.L. and Oliva, R. (2007) Human Sperm DNA Fragmentation: Correlation of TUNEL Results as Assessed by Flow Cytometry and Optical Microscopy. Cytometry A, 71, 1011-1018. http://dx.doi.org/10.1002/cyto.a.20484

[38] Muratori, M., Forti, G. and Baldi, E. (2008) Comparing Flow Cytometry and Fluorescence Microscopy for Analyzing Human Sperm DNA Fragmentation by TUNEL Labeling. Cytometry A, 73, 785-787. http://dx.doi.org/10.1002/cyto.a.20615

[39] Kalyuzhny, A.E. (2011) Combination of TUNEL Assay with Immunohistochemistry for Simultaneous Detection of DNA Fragmentation and Oxidative Cell Damage. Methods in Molecular Biology, 682, 15-27. http://dx.doi.org/10.1007/978-1-60327-409-8_ 2

[40] Mitchell, L.A., De Iuliis, G.N. and Aitken, R.J. (2011) The TUNEL Assay Consistently Underestimates DNA Damage in Human Spermatozoa and Is Influenced by DNA Compaction and Cell Vitality: Development of an Improved Methodology. International Journal of Andrology, 34, 2-13. http://dx.doi.org/10.1111/j.1365-2605.2009.01042.x

[41] Sergerie, M., Mieusset, R., Daudin, M., Thonneau, P. and Bujan, L. (2006) Ten-Year Variation in Semen Parameters and Sperm Deoxyribonucleic Acid Integrity in a Healthy Fertile Man. Fertility and Sterility, 86, 1513.e11-1513.e18. 